OPEN ACCESS

Edited by:

Sarman Singh

All India Institute of Medical

Sciences, India

Reviewed by:

Celio Geraldo Freire-de-Lima,

Federal University of Rio de

Janeiro, Brazil

Lucas Carvalho,

Federal University of Bahia, Brazil

*Correspondence:

Fatima Conceição-Silva fconcei@ioc.fiocruz.br

Fernanda N. Morgado

morgado@ioc.fiocruz.br

Specialty section: This article was submitted to

Parasite and Host,

a section of the journal Frontiers in Cellular and Infection Microbiology

Received: 30 April 2019 Accepted: 04 September 2019 Published: 19 September 2019

Citation:

Conceição-Silva F and Morgado FN

(2019) Leishmania Spp-Host Interaction: There Is Always an Onset,

but Is There an End?

Front. Cell. Infect. Microbiol. 9:330. doi: 10.3389/fcimb.2019.00330

\section{Leishmania Spp-Host Interaction: There Is Always an Onset, but Is There an End?}

\author{
Fatima Conceição-Silva ${ }^{1 *}$ and Fernanda N. Morgado ${ }^{2 *}$ \\ ${ }^{1}$ Laboratory of Immunoparasitology, Oswaldo Cruz Institute, IOC/Fiocruz, Rio de Janeiro, Brazil, ${ }^{2}$ Laboratory of \\ Leishmaniasis Research, Oswaldo Cruz Institute, IOC/Fiocruz, Rio de Janeiro, Brazil
}

For a long time Leishmaniasis had been considered as a neglected tropical disease. Recently, it has become a priority in public health all over the world for different aspects such as geographic spread, number of population living at risk of infection as well as the potential lethality and/or the development of disfiguring lesions in the, respectively, visceral and tegumentary forms of the disease. As a result, several groups have been bending over this issue and many valuable data have been published. Nevertheless, parasite-host interactions are still not fully known and, consequently, we do not entirely understand the infection dynamics and parasite persistence. This knowledge may point targets for modulation or blockage, being very useful in the development of measures to interfere in the course of infection/ disease and to minimize the risks and morbidity. In the present review we will discuss some aspects of the Leishmania spp-mammalian host interaction in the onset of infection and after the clinical cure of the lesions. We will also examine the information already available concerning the parasite strategy to evade immune response mainly at the beginning of the infection, as well as during the parasite persistence. This knowledge can improve the conditions of treatment, follow-up and cure control of patients, minimizing the potential damages this protozoosis can cause to infected individuals.

Keywords: leishmaniasis, parasite evasion mechanisms, immune response, parasite-host interaction, parasite persistence

\section{LEISHMANIASIS: A BRIEF INTRODUCTION}

Leishmaniasis is an infectious disease caused by parasites of the genus Leishmania that affect humans and other animals. They are transmitted by insects popularly known as sand flies (Order Diptera, family Psychodidae, subfamily Phlebotominae) and can cause different clinical presentations, from cutaneous, and/or mucosal lesions (tegumentary leishmaniasis) up to visceral infection with tropism by the lymphohematopoietic system (visceral leishmaniasis). Due to its potential for lethality, mainly in visceral forms, as well as its dispersion in several continents with large population groups under infection risk, it is considered by WHO as one of the priority attention diseases (World Health Organization, 2010, 2017; Alvar et al., 2012).

The resolution WHA60.13, published during the World Health Assembly in 2007, aims to develop different actions all over the world in order to promote leishmaniasis control both by improving diagnosis and treatment access and by establishing or fortifying national control programs (World Wealth Assembly, 2007). Nowadays, leishmaniasis is described in 98 
countries and several others are under risk of infection due to climate changes and/or population mobility (by migration and travel) (Ait Kbaich et al., 2017; Azimi et al., 2017; Baylis, 2017; World Health Organization, 2017, among others). In this sense, several diagnostic possibilities have emerged in recent years, and the serological test rK39 is among the most promising rapid tests due to its high sensitivity and specificity for the diagnosis of visceral leishmaniasis in symptomatic and asymptomatic patients (Maia et al., 2012; Boelaert et al., 2014; Bangert et al., 2018).

In order to develop new drugs and less invasive diagnostic procedure, it is necessary to better understand the parasite-host interaction and the factors that can promote disease severity and control. Several factors have been implicated in determining, or at least facilitating, the development of leishmaniasis in humans (reviewed by Conceição-Silva et al., 2018), and the consensus indicates that the presence of clinically detectable leishmaniasis occurs due to multiple factors related to both parasite and host. In this connection, in the last few years, an increased number of evidences have pointed several mechanisms that can take place according to the necessity for survival from both sides.

At the host side, the presence of malnutrition, comorbidities, extremes of age, amongst others may facilitate the evolution of leishmaniasis to more severe forms, since many of these factors act direct or indirectly on the ability of the immune system to respond adequately to the presence of the parasite (reviewed by Conceição-Silva et al., 2018). For example, in HIV-Leishmania coinfection patients, VL quickly accelerates the onset of AIDS and shortens their life-expectancy. Also, HIV increases the risk of clinical VL and the risk of atypical leishmaniasis (FreitasJunior et al., 2012; Távora et al., 2015; Henn et al., 2018). In addition, during thousands of years, parasites and humans have co-evolved and, consequently, their surviving systems have been structured to avoid danger and damage. As a result, parasites have developed intricate strategies to subvert, modify and/or inhibit the host immune response. Positive selection pressure has improved species survival into the host environment based on more adapted individuals. Thus, the "good" parasite is that one capable of surviving while causing minimal damage to its host. The result of this encounter may lead to equilibrium (parasitic persistence) or disequilibrium (disease) of the parasitehost relationship. This point is easily demonstrated by the clinical disease onset in individuals under immunosuppressive status (recently reviewed by Akuffo et al., 2018; Conceição-Silva et al., 2018) even with no previous story of infection.

Two natural events proving the persistence of parasite are represented by 1 - mucosal lesions produced years after primary cutaneous lesions (Leite et al., 2012; Ávila et al., 2018), and 2- the Post-Kal-azar dermal leishmaniasis (PKDL) after VL recovering (Ganguly et al., 2010; Singh et al., 2012; Zijlstra, 2016). In both cases, the same Leishmania species is able to produce, after healing, a different clinical form from primary manifestations. Although these manifestations appear in part of patients, since mainly Leishmania donovani is responsible for PKDL, and just few Leishmania species can produce mucosal forms, the importance of parasite in these late clinical manifestations is evident. Furthermore, isolates obtained from PKDL patients genetically differ from strains of patients who present just VL (Mishra et al., 2013). These differences may play a role in the pathogenesis of PKDL and in drug resistance to sodium antimony gluconate, miltefosine, and paromomycin (Mishra et al., 2013).

At the parasite side, different pathways to avoid or subvert the immune response have been demonstrated (reviewed by Duque and Descoteaux, 2015; Mandell and Beverley, 2016; ConceiçãoSilva et al., 2018, among others). The mechanisms of escape of Leishmania spp in their hosts is so varied that we decided to focus on some aspects of the interaction, notably those strategies observed at the beginning of infection, escape from NETs, cleavage of molecules from complement system, strategies to entry, and to survive inside permissive cells and subversion of macrophages and lymphocytes, as well as the capacity to use the normal regulatory immunological mechanisms to replicate and to establish infection.

One of the first steps of the Leishmania-host interaction occurs by the metacyclic promatigostes inoculation during the female sand fly feed.

\section{HOW PARASITE PROMOTES SURVIVAL IN A NON-FRIENDLY ENVIRONMENT?}

\section{The First Step: Infection}

Infection begins when a female sand fly interacts with the skin host and injects metacyclic promastigotes into the dermis. The proportion of metacyclic promastigotes delivered by the female sand fly into the skin is responsible for the success of the infection (Giraud et al., 2019). Flies infected for more days contain more parasite burden and are able to deliver higher numbers of parasites into the skin and their infective dose is enriched by non-metacyclic promastigotes (low-quality dose) (Giraud et al., 2019). This fact influences the pathology caused by Leishmania mexicana leading to exacerbated cutaneous lesions, enriched by neutrophils, and associated with low parasite load in the skin of mammalians (Giraud et al., 2019). A high-quality dose containing low quantity of promastigotes $(\sim 100-1,000$ parasites) but enriched by metacyclic promastigotes generates milder lesions with higher parasite load and is more effective in transmitting to other sand flies, showing the influence of parasite-vector relationship on the skin inflammatory response and on the final parasite load in the mammalian host (Giraud et al., 2019). Moreover, the traumatic changes caused by the contact of proboscides with skin and the disruption of the epidermis layers associated with the sand fly saliva induce the endothelial activation and neutrophil infiltration (Peters et al., 2008; Peters and Sacks, 2009). The inflammatory infiltrate generated creates a toxic environment from which promastigotes have to escape to survive. For this, promastigotes have to escape from extracellular toxic environment, enter the host cells, and convert into amastigote form. In this context, components in the sand fly saliva may help promastigotes in this issue. For example, saliva contains endonuclease, which digests Neutrophil Extracellular Traps (NETs) and inhibits blood coagulation, possibly allowing the local spread of promastigotes (Chagas et al., 2014). 
Resident macrophages together with infiltrated neutrophils are the first cells to interact with Leishmania parasite upon infection. Neutrophils may exert a variety of effector mechanisms, such as phagocytosis, enzymes, and antimicrobial proteins release and NET formation (Kennedy and De Leo, 2009). Leishmania amazonensis promastigotes induce NET formation (Guimarães-Costa et al., 2009) and NETs were also demonstrated in active and chronic lesions of Tegumentary Leishmaniasis (TL) caused by Leishmania braziliensis, showing that even amastigotes may induce NET formation (Guimarães-Costa et al., 2009; Morgado et al., 2015). In in vitro system, NETs exerted restraint and toxic effects for L. amazonensis promastigotes (GuimarãesCosta et al., 2009), which could be reverted by the expression of Leishmania - 3'Nucleotidase/Nuclease activity digesting NETs and escaping killing by released NETs (Guimarães-Costa et al., 2014). In patients infected with $L$. braziliensis, ecto-nucleotidase activity is correlated with clinical manifestations: isolates from mucosal lesions presented higher ecto-nucleotidase activity than skin lesions (Leite et al., 2012). Furthermore, higher ectonucleotidase activity is also correlated with higher parasite load, and modulation of immune response by inhibiting dendritic cell activation and NO production (Leite et al., 2012). The interaction between NETs and macrophages favor the survival and persistence of parasites since it stimulates the M2 profile of macrophages, which are susceptible to L. amazonensis infection but unable to kill the parasite (Guimarães-Costa et al., 2017). Recently, L. panamensis resistant strains to miltefosine and meglumine antimoniate were described (Regli et al., 2018). These strains were able to modulate neutrophils stimulating the release of NETs and ROS production and survived better within neutrophils than the drug-susceptible strains (Regli et al., 2018). Altogether, these published data suggest that the induction of NET formation may lead to escape from extracellular effector immune mechanisms, facilitating the access of a permissive cell to parasite infection and persistence.

Still in the extracellular milieu, promastigotes have to survive from the effect of complement molecules. For this, LPG present in the parasite surface interferes with the complement cascade (Hermoso et al., 1991) and with the insertion of membrane attack complex (Puentes et al., 1990). In addition, the metallopeptidase GP63 cleaves the C3b molecule (Brittingham et al., 1995).

To enter host cells, Leishmania spp. uses manose-fucose (Akilov et al., 2007), Fc (Kima et al., 2000), fibronectin (Brittingham et al., 1999), and Toll-like receptors (Kropf et al., 2004), as well as CR1 and CR3 complement receptors (Blackwell et al., 1985; Wenzel et al., 2012). Inside the phagolysossoma, Leishmania spp have to escape from the acid environment, the action of enzymes and the microbicidal effects from oxygen and nitrogen radicals. In $L$. donovani experimental infection, the inhibition of phagolysosomes biogenesis was observed (Matheoud et al., 2013). As an effect of the metallopeptidase GP63 that mediates the cleavage of SNAREs, L. donovani infection prevented NADPH oxidase complex from assembling, altering the $\mathrm{pH}$ and phagosome degradative properties (Matheoud et al., 2013). As a result, antigen presentation via MHC-I was impaired, reducing the $\mathrm{T}$ cell activation (Matheoud et al., 2013).
During parasite-host macrophage interaction, Leishmania spp. infection may exert some impacts on signaling pathways leading to the inability of macrophages to kill intracellular parasites (Awasthi et al., 2003). For example, in experimental infection of BALB/c mice with Leishmania major, the CD40 signaling pathway is impaired (Awasthi et al., 2003). Thus, it results in the impairment of protein kinase $\mathrm{C}(\mathrm{PKC} \alpha$, $\beta I, \beta I I$, and $\varepsilon$ ) (Sudan et al., 2012) and the consequent reduction in p38MAPK phosphorylation and NOS2 expression, resulting in an impairment in killing Leishmania amastigotes (Awasthi et al., 2003). On the other hand, L. major infection enhances PKC $\delta, \zeta$, and $\lambda$ isoforms, promoting ERK1/ERK2 phosphorilation, IL-10 production, and parasite growth (Sudan et al., 2012). These effects can be reverted using anisomycin, a p38MAPK activator, establishing a host-protective memory $\mathrm{T}$ cell response (Awasthi et al., 2003). Leishmania donovani infection differentially regulates small G-proteins: enhances $\mathrm{N}$-Ras expression, whereas it inhibits K-Ras and H-Ras expression (Husein et al., 2018). It also increases extracellular signal-regulated kinase $1 / 2$ phosphorylation and simultaneously decreases p38 phosphorylation, leading to the reduction of IL-12 and the increase of IL-10 expression (Husein et al., 2018). In macular PKDL patients, L. donovani infection decreased leucocyte rolling (L-selectin shedding) and induced up-regulation of the cellular signaling factors involved in pathogenesis (ERK1/2) as well as down regulated the signaling elements (p38 MAPK) involved in the Th1 response (Singh et al., 2018). The role of IL-10-induced immunosuppression in parasite persistence in visceral leishmaniasis and PKDL has already been described (Zijlstra, 2016; Lima et al., 2017; Bunn et al., 2018; Viana et al., 2019). Leishmania infantum subverts the host inflammatory response through the adenosine $\mathrm{A} 2 \mathrm{~A}$ receptor by inducing $\mathrm{CD}^{+}{ }^{+} \mathrm{FOXP}_{3}{ }^{+} \mathrm{T}$ cells and IL-10 expression impairing the development of Th1-type adaptive immunity and promoting the establishment of infection (Lima et al., 2017). In experimental infection with $L$. donovani, the absence of IL-10 resulted in the control of parasite replication, but also caused tissue damage and the rupture of splenic microarchitecture (Bunn et al., 2018). PKDL is characterized by an intermediate position between a Th2 and Th1 response: the Th2 response shows the presence and persistence of IL-10 in the skin that was already present during VL, while systemically the Th1 response that was induced after VL therapy persists with IFN- $\gamma$ production (Zijlstra, 2016).

Although not observed in L. major infection (Späth et al., 2008), in L. donovani infection, the inhibition of nitric oxide production by the protein tyrosine phosphatase (SHP-1) in mice macrophages was demonstrated in vitro and in vivo (Forget et al., 2006). The authors demonstrated that Leishmania major was able to inhibit the activation of JAK2 and ERK1/2 and the transcription factors NF-kB and AP- 1 since SHP- 1 is a negative regulator of these transcription factors (Forget et al., 2006; Blanchette et al., 2008). In addition, infection of macrophages with L. major induces the expression of Monarch-1, a negative regulator of NF-kB activation (Fata et al., 2013). Leishmania infantum infection induces the activation of phosphatidylinositol 3-kinase/Akt and extracellular signal-regulated kinase 1/2 and promotes the cleavage of the nuclear factor-kB p65 $5^{\text {RelA }}$ subunit 
TABLE 1 | Main evasion mechanisms already described for Leishmania species.

\begin{tabular}{|c|c|c|}
\hline $\begin{array}{l}\text { Leishmania } \\
\text { species }\end{array}$ & Escape mechanisms mainly described & Reference \\
\hline L. major & $\begin{array}{l}\text { Impairment in CD40 signaling. } \\
\text { Impairment of protein kinase } \mathrm{C}(\mathrm{PKC} \alpha, \beta \mathrm{I}, \beta \| \text { and } \varepsilon) \text { and enhancement of } \mathrm{PKC} \delta, \zeta \text { and } \lambda \text { isoforms, promoting } \\
\text { ERK1/ERK2 phosphorilation, IL-10 production and parasite growth. } \\
\text { Suppression of IL-2R } \alpha \text { expression by peripheral human T lymphocytes. } \\
\text { Induction of Monarch-1 expression by macrophages, a negative regulator of NF-kB activation. } \\
\text { Hijack of host cell autophagy machinery to reduce T-cell proliferation. } \\
\text { Induction of apoptosis of lymphocytes by the downregulation of Bcl-2 and over-expression of p53 and caspase-3. }\end{array}$ & $\begin{array}{l}\text { Awasthi et al., } 2003 \\
\text { Sudan et al., } 2012 \\
\text { Khodadadi et al., } 2013 \\
\text { Fata et al., } 2013 \\
\text { Crauwels et al., } 2015 \\
\text { Moshrefi et al., } 2017\end{array}$ \\
\hline L. donovani & $\begin{array}{l}\text { Inhibition of nitric oxide production and the activation of JAK2 and ERK1/2 and the transcription factors NF-kB and } \\
\text { AP-1 by the protein tyrosine phosphatase (SHP-1) in macrophages. } \\
\text { Different regulation of small G-proteins, enhancing N-Ras expression, and inhibiting K-Ras and H-Ras expression. } \\
\text { Induction of PD-1 and CTLA-4 expression by lymphocytes. } \\
\text { Induction of PD-L2 expression by macrophages. } \\
\text { Inhibition of phagolysosomes biogenesis, NADPH oxidase complex assembling, altering the pH and phagosome } \\
\text { degradative properties, and inhibiting antigen presentation via MHC-I. } \\
\text { Induction of the transcription factor IRF-5 that limits CD8T cells expansion and inhibits IL-12 expression. }\end{array}$ & $\begin{array}{l}\text { Forget et al., 2006; } \\
\text { Blanchette et al., } 2008 \\
\text { Husein et al., } 2018 \\
\text { Murphy et al., } 1998 \\
\text { Medina-Colorado et al., } \\
2017 \\
\text { Matheoud et al., } 2013 \\
\text { Hammami et al., } 2015\end{array}$ \\
\hline L. braziliensis & $\begin{array}{l}\text { Reduction of NO production and high infection index in vitro. } \\
\text { Decrease of BLT1 receptor, which recognizes the lipid leukotriene B4 (LTB4). } \\
\text { Increase of superoxide dismutase } 1 \text { (SOD1) by macrophages. } \\
\text { Ecto-nucleotidase activity. }\end{array}$ & $\begin{array}{l}\text { Campos et al., } 2008 \\
\text { Morato et al., } 2014 \\
\text { Khouri et al., } 2014 \\
\text { Leite et al., } 2012\end{array}$ \\
\hline L. amazonensis & $\begin{array}{l}\text { Phosphatidylserine exposition. } \\
\text { Activation of NF-kB repressor complex p50/p50 that negatively regulates NOS2 expression interfering with NO } \\
\text { production. } \\
\text { Induction of NETs and stimulation of M2 profile. } \\
\text { Increase of superoxide dismutase } 1 \text { (SOD1) by macrophages. } \\
\text { Downregulation of macrophage iNOS expression via Histone Deacetylase } 1 \text { (HDAC1). }\end{array}$ & $\begin{array}{l}\text { Wanderley et al., } 2009 \\
\text { Calegari-Silva et al., } 2009 \\
\text { Guimarães-Costa et al., } \\
2017 \\
\text { Khouri et al., } 2014 \\
\text { Calegari-Silva et al., } 2018\end{array}$ \\
\hline L. infantum & $\begin{array}{l}\text { Use of apoptosis from host cell as a mean to survive and replicate. The mechanism should be clarified. } \\
\text { Expression of 3'Nucleotidase/Nuclease activity. } \\
\text { Manipulation of AMPK activation. } \\
\text { Production of the enzyme ornithine descarboxylase, which plays a role in the synthesis of tripanothione and the } \\
\text { modulation of the immune response and pathogenesis. } \\
\text { Lower expression of TLR2, TLR9, HLA-DR and TNF- } \alpha \text {, resulting in less control of parasite load. } \\
\text { Induction of MHC Class Ilhigh DC to polarize CD4+T Cells toward a nonprotective T-bet+ IFN-g+IL-10+ phenotype. }\end{array}$ & $\begin{array}{l}\text { Moreira et al., } 2013 \\
\text { Guimarães-Costa et al., } \\
2014 \\
\text { Moreira et al., } 2015 \\
\text { Yadav et al., } 2015 \\
\text { Viana et al., } 2018 \\
\text { Resende et al., } 2013\end{array}$ \\
\hline L. guyanensis & Induction of the up-regulation of the A20 protein, avoiding the inflammasome pathways. & Hartley et al., 2018 \\
\hline
\end{tabular}

by infected DCs (Neves et al., 2010). Therefore, Leishmania can inhibit microbicidal oxygen and nitrogen radicals, enabling them to escape from effector mechanisms upon phagocytosis. Some of these effects could be reversed in vitro using meglumine antimoniate, but nitric oxide production was only recovered using the drug associated with TNF- $\alpha$ (Muniz-Junqueira and de Paula-Coelho, 2008).

In human cutaneous leishmaniasis, the oxidative burst of monocytes is higher than that from healthy donors (Carneiro et al., 2016). However, NO alone is not sufficient to control the parasite load (Carneiro et al., 2016). This capacity to resist or interfere with NO production by macrophages depends on the Leishmania species involved (Table 1; Campos et al., 2008). Therein, L. braziliensis isolated from Mucosal Leishmaniasis patients showed the highest infection index and the lowest NO production in vitro by macrophages when compared to the infection by the other species of subgenus Viannia (Campos et al., 2008). In contrast, $L$. naiffi, which generally causes a benign and autoresolutive infection in humans, showed the lowest infection index and the highest NO production (Campos et al., 2008).
In another study, promastigotes isolated from patients with mucosal leishmaniasis express more thiol-specific antioxidant protein, and were more resistant to nitric oxide and $\mathrm{H}_{2} \mathrm{O}_{2}$ than strains obtained from localized cutaneous leishmaniasis (Ávila et al., 2018). Leishmania amazonensis, which is capable of inducing severe diffuse cutaneous form cursing with high parasite load and inactivation of macrophages, also developed strategies to escape from oxidative effects from phagocytes. For example, $L$. amazonensis activates the NF-kB repressor complex p50/p50 that negatively regulates NOS2 expression interfering with NO production (Calegari-Silva et al., 2009). Leishmania donovani produces ornithine decarboxylase, which plays a role in the synthesis of tripanothione, the major reduced thiol responsible for the modulation of the immune response and pathogenesis in visceral leishmaniasis (Yadav et al., 2015). In this last study, the effects of a recombinant ornithine decarboxylase from $L$. donovani ( $\mathrm{r}$-LdODC) on the immune response of peripheral blood mononuclear cells of patients affected by visceral leishmaniasis were observed (Yadav et al., 2015). The rLdODC induced the production of IL-10 from CD4 T cells and 
the reduced IL-12 and NO production (Yadav et al., 2015). The induction of proinflammatory mediators such as TNF- $\alpha$ and IL-6 through the transcription factor IRF- 5 by $L$. donovani has also been demonstrated (Hammami et al., 2015). IRF-5 also limits CD8 $\mathrm{T}$ cell expansion and inhibits IL-12 expression, favoring the establishment of persistent infection (Hammami et al., 2015).

Leishmania spp can also interfere with immune cell-cell communication, inhibiting an efficient immune response. For example, L. major can suppress IL-2R $\alpha$ expression by peripheral human T lymphocytes (Khodadadi et al., 2013). This suppression impacts the proliferation of $\mathrm{T}$ cells, stimulation of NK cells, and IFN $-\gamma$ production, thus resulting in a failure of immune response. In this sense, $L$. infantum may induce MHC Class II ${ }^{\text {high }}$ DC to polarize $\mathrm{CD}^{+}{ }^{+} \mathrm{T}$ Cells toward a non-protective $\mathrm{T}$-bet ${ }^{+}$ IFN-g ${ }^{+} \mathrm{IL}-10^{+}$phenotype, which is associated with chronicity and prolonged parasite persistence (Resende et al., 2013). Differences in the capability to modulate the effector response from monocytes by both species have also been demonstrated (Viana et al., 2018). Leishmania infantum infections lead to lower expression of TLR2, TLR9, HLA-DR and TNF- $\alpha$, resulting in less control of parasite load, which may reflect upon the distinct clinical course observed in patients presenting visceral and tegumentary leishmaniasis (Viana et al., 2018).

Once the parasite converts into intracellular amastigotes, the next step is dissemination. A study comparing L. majorpromastigotes and amastigotes infection of macrophagesshowed that while infection with promastigotes induced inflammatory mediators, such as TNF- $\alpha$ and chemokines, amastigote infection was silent resulting in increased parasite load (Wenzel et al., 2012).

\section{The Infection Continuity: A Question of Response Subversion to Promote Leishmania spp Survival}

Sand fly saliva is composed of multiple components with a variety of functions and is able to immunomodulate macrophages (Lerner et al., 1991; Morris et al., 2001; Oliveira et al., 2008). Maxadilan, the most well-defined component from Lutzomyia longipalpis saliva, alone decreases TNF- $\alpha$, IL-10 and increases IL-6, IL-8, and IL-12 production in LPS stimulated human macrophages (Costa et al., 2004). In addition, saliva from Lutzomyia longipalpis increases the anti-inflammatory mediator PGE2 and reduces the lipid leukotriene B4 (LTB4), favoring L. infantum infection in C57BL6 mice (Araújo-Santos et al., 2014). Leishmania spp. may also affect macrophage profile and functions. Infection with L. braziliensis leads to the decrease of BLT1 receptor, which recognizes LTB4 (Morato et al., 2014). LTB4-BLT1 recognition activates pro-inflammatory responses and stimulates the leishmanicidal activity of macrophages and neutrophils by inducing ROS secretion (Morato et al., 2014; Plagge and Laskay, 2017). Depending on the species, Leishmania can differently modulate macrophages. For example, infection with $L$. baziliensis promotes the infiltration of intermediate monocytes that express TNF and IL1 $\beta$ and enhance the inflammatory response in human patients (Passos et al., 2015; Santos et al., 2018). LPG from L. braziliensis was able to induce higher TNF- $\alpha$, IL-6, IL-1 $\beta$, and NO production by infected macrophages than LPG from L. infantum (Ibraim et al., 2013). In addition, $L$. braziliensis activates NF-kB, while no ERK activation by L. infantum LPG was demonstrated (Ibraim et al., 2013). In fact, the production of IL- $1 \beta$ by cutaneous leishmaniasis patients is associated with chronic inflammation and tissue damage (Novais et al., 2017). L. amazonensis induces HDAC1, which negatively regulates NOS2 expression contributing to the hyporeactive state of macrophages and to the replication of amastigotes (Calegari-Silva et al., 2018). Leishmania infantum is able to modulate host macrophage mitochondrial metabolism by hijacking the SIRT1-AMPK axis (Moreira et al., 2015). Parasites alter the macrophage metabolism toward aerobic glycolysis (Warburg effect) with a concomitant decrease of mitochondrial function, leading to the accumulation of intracellular ATP (Moreira et al., 2015). Consequently, an activation of AMPK is observed and leads to catabolic processes to restore intracellular energy and nutrients that can nourish the parasite (Moreira et al., 2015). Besides that, Leishmania parasites activate the PERK/eIF2 $\alpha /$ ATF-4 pathway in cultured macrophages and infected human tissue protecting themselves from the harmful consequences of cellular stress, thus contributing to parasite survival and progression of the infection (Dias-Teixeira et al., 2017). Recently, the modulation of human macrophages by L. infantum-MicroRNA hsa-miR-346 demonstrated to play a role in regulating macrophage functions since several MHCor interferon-associated genes are targets for this miRNA (Diotallevi et al., 2018).

Apoptosis is a process of cell death that maintains tissue homeostasis (Trahtemberg and Mevorach, 2017). Apoptotic cells present morphological and functional characteristics, such as chromatin condensation, pyknotic, and fragmented nuclei, apoptotic bodies formation, and phosphatidylserine (PS) exposition (Elmore, 2007; Trahtemberg and Mevorach, 2017). PS is recognized by regulatory receptors, such as TIM3, which inhibits the inflammatory response (Kerr et al., 2018). As an escape mechanism, promastigotes may also inhibit the inflammatory process due to exposition of PS (Wanderley et al., 2009). Different from amastigotes whose entire population expresses PS, part of L. amazonensis promastigotes are $\mathrm{PS}^{+}$and modulate inflammatory infiltrate, while $\mathrm{PS}^{-}$ promastigotes are able to successfully infect macrophages and survive intracellularly due to host phagocyte inactivation and reduction of NO production (Wanderley et al., 2009). Apoptotic parasites stimulate TGF- $\beta$ production, silencing macrophages and favoring the survival of viable parasites (Aga et al., 2002; van Zandbergen et al., 2004). Therefore, efficient in vivo and in vitro infection occurred only when PS positive and negative promastigotes subpopulations were added simultaneously (Wanderley et al., 2009). Apoptoticlike Leishmania also uses host cell autophagy machinery (Crauwels et al., 2015). Therefore, T cell proliferation is inhibited favoring the overall population survival (Crauwels et al., 2015). Autophagy machinery plays a role during homeostasis by clearing apoptotic bodies in a process known as LC3-associated phagocytosis and promotes an anti-inflammatory response with production of IL-10 and TGF- $\beta$ and hampering the production 
of proinflammatory cytokines, such as TNF- $\alpha$, IL-1B, and IL-6 (Crauwels et al., 2015), generating a microenvironment favorable to Leishmania survival and replication.

Still at the beginning of infection, the infiltrating neutrophils rapidly respond to the infection and phagocytize the promastigotes and die generating apoptotic bodies that inhibit the response of macrophages (Afonso et al., 2008; Ribeiro-Gomes and Sacks, 2012). In established infection, apoptosis of host cells has been correlated with disease progression and increase of parasite load, suggesting the parasite can use the normal regulatory process to escape from effector mechanisms from leucocytes (Moreira et al., 2013). Leishmania major infection induces apoptosis of lymphocytes by the down-regulation of Bcl-2 and over-expression of p53 and caspase-3 (Moshrefi et al., 2017). However, how Leishmania spp may use this mechanism to evade immune response has yet to be clarified. In fact, apoptosis of inflammatory cells may occur as a result of cellular exhaustion (Liu et al., 2018). Cellular exhaustion was first described in chronic viral infection and manifested at the beginning of infection, being characterized by the expression of PD-1 receptor (Programmed Death 1) (Barber et al., 2006). $\mathrm{PD}-1$ expression is induced by repeated antigenic stimulation of $\mathrm{T}$ and B lymphocytes (Eichbaum, 2011). The PD-ligand 1 (PD-L1) is constitutively expressed by $\mathrm{B}$ and $\mathrm{T}$ lymphocytes, macrophages and dendritic cells from spleen (Eichbaum, 2011). PD-1 activation induces apoptosis, down-regulates cellular proliferation and cytokine expression (Joshi et al., 2009). PD-1 and CTLA-4 expression by CD8 cells from peripheral blood and spleen were demonstrated in human VL (Gautam et al., 2014) and in L. donovani-infected mice (Murphy et al., 1998). The exhaustion pathway blockage with anti-CTLA- 4 antibody increased IFN- $\gamma$ and IL- 4 expression in murine spleen and liver, as well as accelerated the development of hepatic granulomatous response associated with the reduction of parasite load (Joshi et al., 2009).

Esch et al. (2013) studied dogs with VL that showed CD4 ${ }^{+} \mathrm{PD}-$ $1^{+}$and $\mathrm{CD}^{+}{ }^{+} \mathrm{PD}-1^{+}$cells in peripheral blood. These cells presented reduced proliferation index, as wells as reduced IFN$\gamma$ expression. Blockage of the exhaustion pathway in vitro recovered the $\mathrm{T}$ cell effector functions, such as proliferation index and oxidative radical production. As a result, the parasite load was partially controlled by monocytes. Exhaustion of macrophages has also been demonstrated in L. donovani infection (Medina-Colorado et al., 2017). The blockage of PD-L2 was able to induce a reduction in arginase- 1 and to control the parasite load; however, no alterations in IFN- $\gamma$ nor NOS2 were demonstrated (Medina-Colorado et al., 2017). Despite the Th1 response induced and the IFN- $\gamma$ expression detected during leishmaniasis, amastigotes are able to survive probably by using normal regulatory mechanisms developed by the immune system that prevents tissue damage and maintains the homeostasis. In this context (Kong et al., 2017), observed that IFN- $\gamma$ enhanced $L$. donovani growth and induced the counter-regulatory molecules STAT3, IL-10, Arg1, Ido1, and Irg1 in splenic macrophages, which suggests that splenic macrophages in VL are conditioned to respond to macrophage activation signals with a counter-regulatory response, which is ineffective and even disease-promoting (Kong et al., 2017). M2 macrophages were also observed during Leishmania spp infection (Moreira et al., 2016; Hu et al., 2018; Kumar et al., 2018; Lee et al., 2018). The M2 profile has been described as a cell type that participates in the processes of cellularity reduction in the inflammatory infiltrate, tissue remodeling, and healing (Tomiotto-Pellissier et al., 2018). In this regard, it produces IL-10, TGF-b, and endothelium growth factors make a cell unable to express NOS2 and kill intracellular amastigotes, favoring Leishmania replication and persistence.

Recently, the capacity of Leishmania spp to modify its genome constitution in order to better adapt to different environments has been demonstrated for L. donovani, L. major, and L. tropica complexes (Prieto Barja et al., 2017; Bussotti et al., 2018). Aneuploidy has been described for Leishmania parasites and this phenomenon generates karyotypic fluctuations that are correlated with phenotypic variations, impacting the proliferative, and infectivity capacities (Prieto Barja et al., 2017). Leishmania clones containing beneficial haplotypes selected by the environment give rise to specific copy number variation profiles that could represent a fitness gain to new hostile environments (Bussotti et al., 2018). Therefore, Leishmania is able to change its chromosome and gene copy number to adapt to environmental changes (Prieto Barja et al., 2017; Bussotti et al., 2018). In this sense, the microenvironment generated by immune cells from the mammalian host or by anti-Leishmania drugs may constitute a bottle neck for the selection of better adapted clones, enabling the persistence of parasites. For example, the allopurinol-resistance of L. infatum strain was associated with chromosome and gene copy number variations (Yasur-Landau et al., 2018). The gene encoding the s-adenosylmethionine synthetase (METK) showed diminished copy numbers in allopurinol-resistance strains (Yasur-Landau et al., 2018). The deletion of the gene LinJ.36.2510 that encodes 24-sterol methyltransferase was associated to amphotericin B-resistance (Rastrojo et al., 2018). And whole genomic sequencing of L. mexicana strain showed an association between anphotericin $\mathrm{B}$ resistance and mutation of the sterol biosynthesis gene (Pountain et al., 2019). Moreover, a comparative proteomic analysis revealed the role of the iron superoxide dismutase in miltefosine resistance of $L$. donovani strains (Veronica et al., 2019). In another study, genomic analysis of L. infantum strains evidenced an association between deletion or mutations in LiMT and LiRos3 genes and miltefosine-resistance (Mondelaers et al., 2016). Finally, the increase of thiol levels was associated to antimony-resistance indicating that the redox metabolism has a role in the antimony-resistance of new world VL isolates (Magalhães et al., 2018).

Once the parasite is able to successfully establish growth and survival in the cells from mammalian host, clinical disease can be detected. However, a certain number of infected individuals are able to control parasite replication as well as the immune response, becoming permissive to parasite persistence. In this case they are considered infected but not sick. In this context, patients with subclinical infection with L. braziliensis may present more $\mathrm{CD}^{+}$IFN- $\gamma^{+}$cells and less Cytotoxic $\mathrm{CD} 8^{+} \mathrm{T}$ cells than patients manifesting cutaneous leishmaniasis (Cardoso et al., 

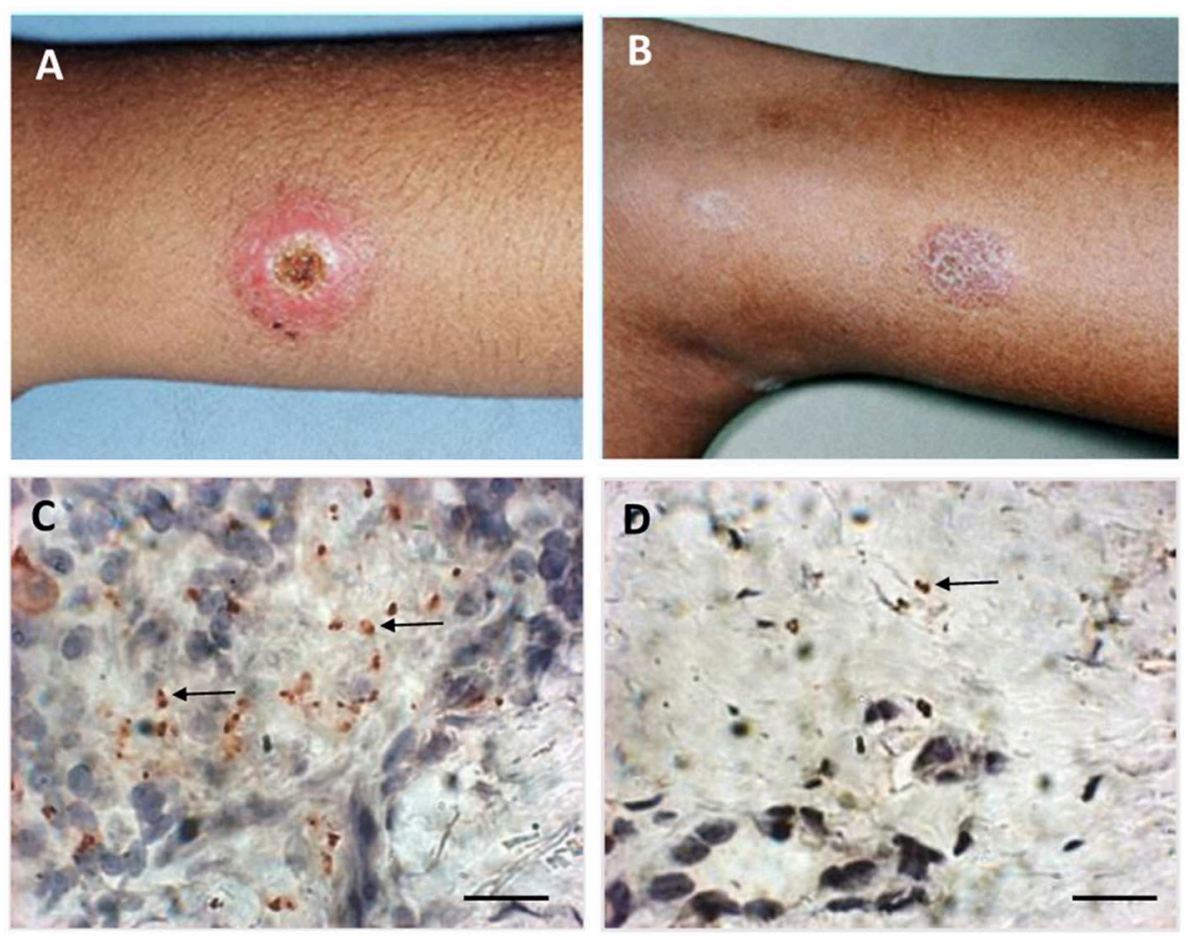

FIGURE 1 | Macroscopic and microscopic aspects of active lesion and scar of American Tegumentary Leishmaniasis. (A) Active lesion-single ulcer with elevated borders and granulomatous aspect in center. (B) Scar-atrophic scar after successful treatment. (C) Several amastigotes detected by immunohistochemistry (arrows) involved by a granulomatous reaction in an active lesion. (D) Two amastigotes (arrow) detected by immunohistochemistry near a discrete inflammatory reaction characterized by cell niches in a scar. Magnification bar $=10 \mu \mathrm{m}$.

2015). However, even these subclinical patients maintain latent parasites that may reactivate in case of immunosuppression (Conceição-Silva et al., 2018). How do parasites persist in mammalian tissues? How does mammalian host contain parasite replication? Answering these questions is crucial to understand the role of both sides to survive without serious damage. Consequently, this knowledge may improve the design of new methods for diagnosis, the development of new drugs, as well as the way to construct a vaccine.

\section{IS THERE AN END IN LEISHMANIA SPP INFECTION? AN UPDATE}

Recently, some factors enrolled in parasite persistence were reviewed (Conceição-Silva et al., 2018). In this connection, the Leishmania spread and persistence in different sites have been well-characterized by different authors. Thus, it was already described that in active cutaneous leishmaniasis patients, the parasite can be present in extralesional sites (Romero et al., 2010; Canário et al., 2019). In this subject, Canário et al. (2019) showed that positivity in healthy mucosa was high in patients with more severe cutaneous lesions and those who needed to be treated longer. However, we still do not know whether parasite burden can influence parasite persistence. Evidences of parasite persistence were not restricted to cutaneous leishmaniasis. In visceral leishmaniasis, parasites may persist after clinical cure of primary manifestations leading to PKDL (Ganguly et al., 2010; Singh et al., 2012; Zijlstra, 2016) or to visceral leishmaniasis reactivation in HIV patients (Freitas-Junior et al., 2012; Távora et al., 2015; Henn et al., 2018). In addition, the presence of some differences in evasion mechanisms according to Leishmania infection produced by different species (de Freitas et al., 2016, among others) has been shown.

Direct or indirect evidences of parasite persistence after healing have been demonstrated since the 1990's (reviewed by Conceição-Silva et al., 2018) (Figure 1). Thus, the importance of the mouse genetic background in the development of disease or parasite persistence has been explored by different research groups (reviewed by Launois et al., 1997; Fowell and Locksley, 1999; Conceição-Silva et al., 2018). In addition, Leishmania profile has also been implicated in different degrees of infection and healing (De Luca and Macedo, 2016). It was already discussed the Leishmania capacity to modify its genome in order to increase the survival in hostile environment (Prieto Barja et al., 2017; Bussotti et al., 2018, see above). This phenomenon would help parasite to survive either during active disease or healing phase.

One of the first pieces of information about how parasite could persist after leishmaniasis healing showed that parasites could subvert the production of reactive nitrogen and oxygen intermediates and modulate the cytokine production, such as interleukin 12, by the host cells (Bogdan et al., 1996; Stenger 
et al., 1996; Bogdan and Röllinghoff, 1998). These functions have been detected both in vitro and in vivo using mouse model of L. major infection. Later on, in animal model, it was shown that, in addition to the parasites inside macrophages, $40 \%$ of the persistent parasites were associated with fibroblasts with reduced expression of NOS2, pointing the importance of these cells to promote parasite survival (Bogdan et al., 2000). It was also demonstrated that GP63 metalloprotease from parasite can inhibit key microbicidal activity by altering antigen presentation and important metabolic and signaling pathways subverting macrophage function in controlling parasite growth (reviewed by Duque and Descoteaux, 2015; Soulat and Bogdan, 2017). In addition, it was also shown that Leishmania parasites harboring Leishmania RNA virus 1 (LRV1) can promote macrophage survival via LRV1 recognition through TLR-3. The authors showed in an in vitro model the possibility of LRV1 interference leading therefore to an increased infection in macrophages (Eren et al., 2016). Hence, the concomitant presence of parasitized macrophages and fibroblasts could produce a balance between death and survival, which would allow the control of parasite growth via continuous immunological stimulus and at the same time would allow a continuous presence of live parasites. In this sense, the persistence parasite at the primary infection site and as a result the continuous antigenic stimulus that leads to long-lasting immunity to reinfection was discussed previously (Okwor and Uzonna, 2008). Nowadays, pieces of evidence of parasite persistence in leishmaniasis are getting more robust. However, we still do not know a real percentage of patients that maintain a tissue parasitism and exactly how the host keeps the parasite under control. Hence, detailed information of how it does occur and the implication of this persistence in the protection to reinfection are still under construction. As tissue parasite distribution seems to be heterogeneous, and different methodological approaches can influence the positivity, one cannot affirm that negative cases reached a sterile healing. In this context, Morgado et al. (2010) showed by immunohistochemistry a gradual reduction of inflammatory reaction after clinical cure, which could be observed even in 3-year-old scars (Morgado et al., 2010). The maintenance of inflammatory profile restrict to niches of cells was associated with the evidence of parasites in 2 scars from evaluated patients (Conceição-Silva et al., 2010; Morgado et al., 2010).

PCR detection of parasites has been widely used as a method to identify Leishmania spp in different tissues, but the primer design is considered crucial to detect parasites, since it has been shown that the use of different primers can produce different percentage of positivity (Romero et al., 2010). Nevertheless, parasites have been detected by PCR in different tissues upon infection, even in the absence of clinical disease. Authors have reported the presence of viable parasites in nasal, oral and conjunctival mucosa as well as in blood mononuclear cells, tonsils and normal skin in asymptomatic individuals and also in patients with isolated cutaneous lesions, demonstrating parasite dissemination without evidences of disease (Martinez et al., 1992; de Oliveira Camera et al., 2006; Vergel et al., 2006; Figueroa et al., 2009; Romero et al., 2010; Rosales-Chilama et al., 2015, among others). Figueroa et al. (2009) showed the presence of
Leishmania spp in $81 \%$ of nasal tissues of patients with active cutaneous leishmaniasis without clinical signs of nasal lesion. In addition, Martinéz-Valencia et al. (2017) detected by PCRSouthern blot a percentage of positivity in $30 \%$ of the healed patients evaluated 13 weeks after treatment initiation. RosalesChilama et al. (2015) detected parasites in $40 \%$ of healthy individuals living in endemic areas and presenting positivity to Montenegro skin test $(\mathrm{MST}+)$. These authors were able to demonstrate parasite viability in 59\% of the MST+ individuals. Interestingly, they were also able to detect parasites in few negative MST volunteers. Taken together, these results confirm the dissemination of Leishmania parasites in different host tissues during the active disease. They also confirm the persistence of parasites in humans after healing, and most importantly, even in healthy individuals without clinical signs of past active or healed tegumentary leishmaniasis.

Protozoan persistence seems to be very frequent in infected individuals, and the onset of an immunosuppression can lead to a recrudescent disease, even in those cases in which the primo infection was silent (discussed in Conceição-Silva et al., 2018). In leishmaniasis, the distribution of the parasite in the tissues from mammalian host appears to occur very early during the infection. In this sense, these results presented above confirm that, at least in leishmaniasis caused by the subgenus Viannia, parasites are precociously located in the mucosae of the upper airways and digestive tracts. However, it has not yet been proven whether this fact facilitates the appearance of secondary mucosal lesions.

What are the advantages or disadvantages of parasite persistence to the host? One possibility is to protect individuals against new infection. However, it was already demonstrated that, at least in mouse model, the immune response elicited by the persistent parasite do not always avoid the possibility of a re-infection (Mandell and Beverley, 2016, among others). On the other hand, the infection does not necessarily evolve into the disease, and even if reinfection is not avoided, the persistence of the parasite may prevent the development of clinical manifestations as long as the immune system is competent. The understanding of this complex host-parasite interaction and the identification of favorable and effective immune responses capable maintaining this equilibrium could be used in vaccine development (Okwor and Uzonna, 2008; De Luca and Macedo, 2016). In addition, Mandell and Beverley (2016) discussed that persistent infection of $L$. major would work as a "natural vaccination" in a condition known as concomitant immunity. Although concomitant immunity seems to be an advantage for the host, this interaction also promotes a potential dangerous condition since if one of the actors modifies the profile (i.e., increased parasite virulence or immunosuppression) the host-parasite equilibrium can be broken leading to the development of severe disease. In this context, the authors showed in a mouse model of leishmaniasis resistance that after a secondary challenge parasites are able to colonize and persist as much as the parasites from the primary infection. However, disease is weak when compared with the primary clinic onset. According to the authors, these results indicated that this strategy would facilitate the generation of parasite diversity during the life cycle maintenance. The same authors (Mandell 
and Beverley, 2017), using mouse model of Leishmania major infection, described the presence of two parasite populations: one with normal replication rate and a second one with very low replication. In addition, they also demonstrated parasites inside $\mathrm{NOS}^{+}$cells, indicating a dynamic control of parasite burden as the number of parasites keeps almost the same throughout the study. They concluded that the constant parasite replication and death are implicated in concomitant immunity and thus are beneficial to both parasite and host. It was not observed an attenuation of NO production by the increase of substrate competition. Both NOS2 and arginase utilize Larginine as substrate and Paduch et al. (2019) demonstrated that Arginase I (Arg1)-deficient C57BL/6 mice were able to control Leishmania infection as much as the wild type. The absence of Arg1 did not affect parasite burden, NO production, or host cell parasitism. In wild type, they detected Arg1 in skin during active lesions but not in healed tissue. The authors also showed parasites in NOS2 negative areas enriched by myeloid cells and fibroblasts. In conclusion, the authors indicated that Arg1 is not essential to parasite control and lesion healing. On the other hand, arginase was already detected in Leishmania parasites, mainly in glycosomes (da Silva et al., 2012; SoaresBezerra et al., 2013). Arginase pathway is necessary to produce polyamines, which have multiple roles in stabilizing nucleic acids and membranes, as well as regulating cell growth and differentiation. In this context, it has been demonstrated the importance of arginase activity in parasites, since replication is mainly dependent on polyamines (Badirzadeh et al., 2017). Nevertheless, it has already been demonstrated a NO production by Leishmania parasites (Géigel and Leon, 2003; Genestra et al., 2003a,b,c), and Leishmania-NO seems to have a role during hostparasite interaction (Temporal et al., 2005; Badirzadeh et al., 2017).

Recently, Holowka et al. (2016) studied the influence of Leishmania-encoded othologs of macrophage migration inhibitory factor in parasite survival and persistence, using $\mathrm{KO}$ parasites $\left(\mathrm{mif}^{-/-}\right)$to cytokine macrophage migration inhibitory factor (MIF) and a wild type $\left(\mathrm{mif}^{+/+}\right)$as control. The results showed that mice infected with mif $^{-/-}$parasites had three times less parasites, a decrease in antigen presenting cells activation, as well as in T cell priming and CD4 effector cells, leading to diminished inflammation signs. On the other hand, the infection promoted differences in the expression of exhaustion markers when compared with the infection produced by the mif ${ }^{+/+}$

\section{REFERENCES}

Afonso, L., Borges, V. M., Cruz, H., Ribeiro-Gomes, F. L., Dos Reis, G. A., Dutra, A. N., et al. (2008). Interactions with apoptotic but not with necrotic neutrophils increase parasite burden in human macrophages infected with Leishmania amazonensis. J. Leukoc. Biol. 84, 389-396. doi: 10.1189/jlb. 0108018

Aga, E., Katschinski, D. M., van Zandbergen, G., Laufs, H., Hansen, B., Müller, K., et al. (2002). Inhibition of the spontaneous apoptosis of neutrophil granulocytes by the intracellular parasite Leishmania major. J. Immunol. 169, 898-905. doi: 10.4049/jimmunol.169.2.898
Leishmania major. Taken the results together, the authors pointed out the influence of MIF produced by L. major to facilitate parasite persistence. In this aspect, Soulat and Bogdan (2017) reviewed the influence of parasites and host phosphatases on the host immune response mainly by modulating macrophage function. This group of molecules would act deactivating phagocytes' host, by inhibiting or stimulating different pathways of activation. One example, amongst others, is the reduced ROS release provoked by GP63, one of the most abundant Leishmania surface molecules. Other phosphatases can also act on macrophages function, allowing parasite survival (reviewed by Soulat and Bogdan, 2017).

\section{FINAL CONSIDERATIONS}

In summary, results published until now point out an important influence of Leishmania species and their intrinsic diversity to promote and sustain parasite survival and persistence after infection. It could be detected in patients after clinical disease healing as well as in healthy individuals from endemic areas, without any signs of past sickness, and in tissues where no clinical signs of lesion were observed. Understanding the dynamic of parasite spread and tropism (if any), and the evasion mechanisms enrolled in persistence can indicate new steps for the design of new drugs and vaccines in order to control leishmaniasis.

\section{AUTHOR CONTRIBUTIONS}

FC-S and FM conceived the manuscript and wrote, reviewed, and approved the manuscript. FC-S conceived the figure. FM conceived the table.

\section{FUNDING}

This study was funded by PAEF-IOC-Fiocruz (IOC-023-FIO-182-47) and by CNPq-Universal (421223/2018-9).

\section{ACKNOWLEDGMENTS}

We would like to thank Drs. A. Schubach, M. Lyra, and M. I. F. Pimentel from the LaPClin Vigileish-Evandro Chagas National Institute of Infectious Diseases -INI- Fiocruz for the photos in Figure 1, and Dr. L. L. Leon for the valuable discussion on parasite $\mathrm{NO}$ and arginase. 
Alvar, J., Vélez, I. D., Bern, C., Herrero, M., Desjeux, P., Cano, J., et al. (2012). Control team. Leishmaniasis worldwide and global estimates of its incidence. PLoS ONE 7:e35671. doi: 10.1371/journal.pone.0035671

Araújo-Santos, T., Prates, D. B., França-Costa, J., Luz, N. F., Andrade, B. B., Miranda, J. C., et al. (2014). Prostaglandin E2/leukotriene B4 balance induced by Lutzomyia longipalpis saliva favors Leishmania infantum infection. Parasit. Vect. 7:601. doi: 10.1186/s13071-014-0601-8

Ávila, L. R., Gomes, C. M., Oliveira, P. G., Gomes, R. S., Vinaud, M. C., Dorta, M. L., et al. (2018). Promastigote parasites cultured from the lesions of patients with mucosal leishmaniasis are more resistant to oxidative stress than promastigotes from a cutaneous lesion. Free Radical. Biol. Med. 129, 35-45. doi: 10.1016/j.freeradbiomed.2018.09.005

Awasthi, A., Mathur, R., Khan, A., Joshi, B. N., Jain, N., Sawant, S., et al. (2003). CD40 signaling is impaired in L. major-infected macrophages and is rescued by a p38MAPK activator establishing a host-protective memory $\mathrm{T}$ cell response. J. Exp. Med. 197, 1037-1043. doi: 10.1084/jem.20022033

Azimi, F., Shirian, S., Jangjoo, S., Ai, A., and Abbasi, T. (2017). Impact of climate variability on the occurrence of cutaneous Leishmaniasis in Khuzestan Province, southwestern Iran. Geospat. Health. 12:478. doi: 10.4081/gh.2017.478

Badirzadeh, A., Taheri, T., Taslimi, Y., Abdissamadi, Z., Heidari-Kharaji, M., Gholami, E., et al. (2017). Arginase activity in pathogenic and nonpathogenic species of Leishmania-parasites. PLoS Negl. Trop. Dis. 11:e0005774. doi: 10.1371/journal.pntd.0005774

Bangert, M., Flores-Chávez, M. D., Llanes-Acevedo, I. P., Arcones, C., Chicharro, C., García, E., et al. (2018). Validation of rK39 immunochromatographic test and direct agglutination test for the diagnosis of Mediterranean visceral leishmaniasis in Spain. PLoS Negl. Trop. Dis. 12:e0006277. doi: 10.1371/journal.pntd.0006277

Barber, D. L., Wherry, E. J., Masopust, D., Zhu, B., Allison, J. P., Sharpe, A. H., et al. (2006). Restoring function in exhausted CD8 T cells during chronic viral infection. Nature 439, 682-687. doi: 10.1038/nature04444

Baylis, M. (2017). Potential impact of climate changes on emerging vector-borne and other infections in the UK. Environ. Health 16:112. doi: $10.1186 / \mathrm{s} 12940-017-0326-1$

Blackwell, J. M., Ezekowitz, R. A., Roberts, M. B., Channon, J. Y., Sim, R. B., and Gordon, S. (1985). Macrophage complement and lectin-like receptors bind Leishmania in the absence of serum. J. Exp. Med. 162, 324-331. doi: $10.1084 /$ jem.162.1.324

Blanchette, J., Abu-Dayyeh, I., Hassani, K., Whitcombe, L., and Olivier, M. (2008). Regulation of macrophage nitric oxide production by the protein tyrosine phosphatase Src homology 2 domain phosphotyrosine phosphatase 1 (SHP-1). Immunology 127, 123-133. doi: 10.1111/j.1365-2567.2008.02929.x

Boelaert, M., Verdonck, K., Menten, J., Sunyoto, T., van Griensven, J., Chappuis, F., et al. (2014). Rapid tests for the diagnosis of visceral leishmaniasis in patients with suspected disease. Cochrane Database Syst. Rev. 2014:CD009135. doi: 10.1002/14651858.CD009135.pub2

Bogdan, C., Donhauser, N., Döring, R., Röllinghoff, M., Diefenbach, A., and Rittig, M. G. (2000). Fibroblasts as host cells in latent leishmaniosis. J. Exp. Med. 191, 2121-2130. doi: 10.1084/jem.191.12.2121

Bogdan, C., Gessner, A., Solbach, W., and Röllinghoff, M. (1996). Invasion, control and persistence of Leishmania parasites. Curr. Opin. Immunol. 8, 517-525. doi: 10.1016/S0952-7915(96)80040-9

Bogdan, C., and Röllinghoff, M. (1998). The immune response to Leishmania: mechanisms of parasite control and evasion. Int. J. Parasitol. 28, 121-134. doi: 10.1016/S0020-7519(97)00169-0

Brittingham, A., Chen, G., McGwire, B. S., Chang, K. P., and Mosser, D. M. (1999). Interaction of Leishmania gp63 with cellular receptors for fibronectin. Infect. Immun. 67, 4477-4484.

Brittingham, A., Morrison, C. J., McMaster, W. R., McGwire, B. S., Chang, K. P., and Mosser, D. M. (1995). Role of the Leishmania surface protease gp63 in complement fixation, cell adhesion, and resistance to complement-mediated lysis. J. Immunol. 155, 3102-3111.

Bunn, P. T., Montes de Oca, M., de Labastida Rivera, F., Kumar, R., Ng, S. S., Edwards, C. L., et al. (2018). Distinct roles for CD4+ Foxp3+ regulatory T cells and IL-10-mediated immunoregulatory mechanisms during experimental visceral Leishmaniasis caused by Leishmania donovani. J. Immunol. 201, 3362-3372. doi: 10.4049/jimmunol.1701582
Bussotti, G., Gouzelou, E., CôrtesBoité, M., Kherachi, I., Harrat, Z., Eddaikra, N., et al. (2018). Leishmania genome dynamics during environmental adaptation reveal strain-specific differences in gene copy number variation, karyotype instability, and telomeric amplification. MBio 9:e01399-e01318. doi: $10.1128 / \mathrm{mBio} .01399-18$

Calegari-Silva, T. C., Pereira, R. M., De-Melo, L. D., Saraiva, E. M., Soares, D. C., Bellio, M., et al. (2009). NF-kappaB-mediated repression of iNOS expression in Leishmania amazonensis macrophage infection. Immunol. Lett. 127, 19-26. doi: 10.1016/j.imlet.2009.08.009

Calegari-Silva, T. C., Vivarini, A. C., Pereira, R. M. S., Dias-Teixeira, K. L., Rath, C. T., Pacheco, A. S. S., et al. (2018). Leishmania amazonensis downregulates macrophage iNOS expression via histone deacetylase 1 (HDAC1): a novel parasite evasion mechanisms. Eur. J. Immunol. 48, 1188-1198. doi: 10.1002/eji.201747257

Campos, M. B., De Castro Gomes, C. M., de Souza, A. A., Lainson, R., Corbett, C. E., and Silveira, F. T. (2008). In vitro infectivity of species of Leishmania (Viannia) responsible for American cutaneous leishmaniasis. Parasitol. Res. 103, 771-776. doi: 10.1007/s00436-008-1039-8

Canário, A., Queiroz, M., Cunha, G., Cavalcante, T., Riesz, V., Sharma, R., et al. (2019). Presence of parasite DNA in clinically unaffected nasal mucosa during cutaneous leishmaniasis caused by Leishmania (Viannia) braziliensis. Clin. Microbiol. Infect. 25, 515.e5-515.e7. doi: 10.1016/j.cmi.2018.12.027

Cardoso, T. M., Machado, Á., Costa, D. L., Carvalho, L. P., Queiroz, A., Machado, P., et al. (2015). Protective and pathological functions of CD8+ $\mathrm{T}$ cells in Leishmania braziliensis infection. Infect. Immun. 83, 898-906. doi: 10.1128/IAI.02404-14

Carneiro, P. P., Conceição, J., Macedo, M., Magalhães, V., Carvalho, E. M., and Bacellar, O. (2016). The role of nitric oxide and reactive oxygen species in the killing of leishmania braziliensis by monocytes from patients with cutaneous Leishmaniasis. PLoS ONE 11:e0148084. doi: 10.1371/journal.pone.0148084

Chagas, A. C., Oliveira, F., Debrabant, A., Valenzuela, J. G., Ribeiro, J. M., and Calvo, E. (2014). Lundep, a sand fly salivary endonuclease increases Leishmania parasite survival in neutrophils and inhibits XIIa contact activation in human plasma. PLoS Pathog. 10:e1003923. doi: 10.1371/journal.ppat.1003923

Conceição-Silva, F., Leite-Silva, J., and Morgado, F. N. (2018). The binomial parasite-host immunity in the healing process and reactivation of human tegumentary leishmaniasis. Front. Microbiol. 9:1308. doi: $10.3389 /$ fmicb. 2018.01308

Conceição-Silva, F., Morgado, F. N., Costa-Santos, M., Miranda-Nascimento, C., and Oliveira-Mendes, S. (2010). Leishmania braziliensis and in situ host immune response: dispute or partnership? Rev. Soc. Bras. Med. Trop. 43, 63-70.

Costa, D. J., Favali, C., Clarêncio, J., Afonso, L., Conceição, V., Miranda, J. C., et al. (2004). Lutzomyia longipalpis salivary gland homogenate impairs cytokine production and costimulatory molecule expression on human monocytes and dendritic cells. Infect. Immun. 72, 1298-1305. doi: 10.1128/IAI.72.3.1298-1305.2004

Crauwels, P., Bohn, R., Thomas, M., Gottwalt, S., Jäckel, F., Krämer, S., et al. (2015). Apoptotic-like Leishmania exploit the host's autophagy machinery to reduce T-cell-mediated parasite elimination. Autophagy 11, 285-297. doi: 10.1080/15548627.2014.998904

da Silva, M. F. L., Zampieri, R. A., Muxil, S. M., Beverley, S. M., and FloeterWinter, L. M. (2012). Leishmania amazonensis arginase compartimentalization in the glycosome is important for parasite infectivity. PLoS ONE 7:234022. doi: 10.1371/journal.pone.0034022

de Freitas, E. O., Leoratti, F. M., Freire-de-Lima, C. G., Morrot, A., and Feijó, D. F. (2016). The contribution of immune evasive mechanisms to parasite persistence in visceral leishmaniasis. Front. Immunol. 7:153. doi: 10.3389/fimmu.2016.00153

De Luca, P. M., and Macedo, A. B. (2016). Cutaneous Leishmaniasis vaccination: a matter of quality. Front. Immunol. 7:151. doi: 10.3389/fimmu.2016.00151

de Oliveira Camera, P., Junger, J., do Espírito Santo Silva Pires, F., Mattos, M., Oliveira-Neto, M. P., Fernandes, O., et al. (2006). Haematogenous dissemination of Leishmania (Viannia) braziliensis in human American tegumentary leishmaniasis. Trans. R. Soc. Trop. Med. Hyg. 100, 1112-1117. doi: $10.1016 /$ j.trstmh.2006.02.014

Dias-Teixeira, K. L., Calegari-Silva, T. C., Medina, J. M., Vivarini, Á. C., Cavalcanti, Á., Teteo, N., et al. (2017). Emerging role for the PERK/eIF2 $\alpha /$ ATF4 in 
human cutaneous Leishmaniasis. Sci. Rep. 7:17074. doi: 10.1038/s41598-01717252-x

Diotallevi, A., De Santi, M., Buffi, G., Ceccarelli, M., Vitale, F., Galluzzi, L., et al. (2018). Leishmania infection induces microRNA hsa-miR346 in human cell line-derived macrophages. Front. Microbiol. 9:1019. doi: $10.3389 /$ fmicb.2018.01019

Duque, G. A., and Descoteaux, A. (2015). Leishmania survival in macrophages: were the ends justify the means. Curr. Opin. Microbiol. 26, 32-40. doi: 10.1016/j.mib.2015.04.007

Eichbaum, Q. (2011). PD-1 signaling in HIV and chronic viral infectionpotential for therapeutic intervention? Curr. Med. Chem. 18, 3971-3980. doi: 10.2174/092986711796957239

Elmore, S. (2007). Apoptosis: a review of programmed cell death. Toxicol. Pathol. 35, 495-516. doi: 10.1080/01926230701320337

Eren, R. O., Reverte, M., Rossi, M., Hartley, M. A., Castiglioni, P., Prevel, F., et al. (2016). Mammalian innate immune response to a Leishmania-resident RNA virus increases macrophage survival to promote parasite persistence. Cell Host Microbe. 20, 318-328. doi: 10.1016/j.chom.2016.08.001

Esch, K. J., Juelsgaard, R., Martinez, P. A., Jones, D. E., and Petersen, C. A. (2013). Programmed death 1-mediated T cell exhaustion during visceral leishmaniasis impairs phagocyte function. J. Immunol. 191, 5542-5550. doi: 10.4049/jimmunol.1301810

Fata, A., Mahmoudian, M., Varasteh, A., and Sankian, M. (2013). Monarch-1 activation in murine macrophage cell line (J774 A.1) infected with iranian strain of Leishmania major. Iran J. Parasitol. 8, 207-211.

Figueroa, R. A., Lozano, L. E., Romero, I. C., Cardona, M. T., Prager, M., Pacheco, R., et al. (2009). Detection of Leishmania in unaffected mucosal tissues of patients with cutaneous leishmaniasis caused by Leishmania (Viannia) species. J. Infect. Dis. 200, 638-646. doi: 10.1086/600109

Forget, G., Gregory, D. J., Whitcombe, L. A., and Olivier, M. (2006). Role of host protein tyrosine phosphatase SHP-1 in Leishmania donovaniinduced inhibition of nitric oxide production. Infec. Immun. 74, 6272-6279. doi: 10.1128/IAI.00853-05

Fowell, D. J., and Locksley, R. M. (1999). Leishmania major infection of inbred mice: unmasking genetic determinants of infectious diseases. Bioessays 21, 510-518. doi: 10.1002/(SICI)1521-1878(199906)21:6<510::AID-BIES7>3.0. $\mathrm{CO} ; 2-5$

Freitas-Junior, L. H., Chatelain, E., Kim, H. A., and Siqueira-Neto, J. L. (2012). Visceral leishmaniasis treatment: what do we have, what do we need and how to deliver it? Int. J. Parasitol. 2, 11-19 doi: 10.1016/j.ijpddr.2012.01.003

Ganguly, S., Das, N. K., Barbhuiya, J. N., and Chatterjee, M. (2010). Postkala-azar dermal leishmaniasis - an overview. Int. J. Dermatol. 49, 921-931. doi: 10.1111/j.1365-4632.2010.04558.x

Gautam, S., Kumar, R., Singh, N., Singh, A. K., Rai, M., Sacks, D., et al. (2014). CD8 T cell exhaustion in human visceral leishmaniasis. J. Infect. Dis. 209, 290-299. doi: 10.1093/infdis/jit401

Géigel, L. F., and Leon, L. L. (2003). Cyclic 3'-5'guanoside monophosphatedependent activity in Leishmania amazonensis. Mem. Inst. Oswaldo Cruz. 98, 499-500. doi: 10.1590/S0074-02762003000400012

Genestra, M., de Souza, W. J., Cysne-Finkelstein, L., and Leon, L. L. (2003b). Comparative analysis of the nitric oxide production by Leishmania sp. Med. Microbiol. Immunol. 192, 217-223. doi: 10.1007/s00430-003-0176-z

Genestra, M., Echevarria, A., Cysne-Finkelstein, L., Vignólio-Alves, L., and Leon, L. L. (2003a). Effect of amidine derivatives on nitric oxide production by Leishmania amazonensis promastigotes and axenic amastigotes. Nitric Oxide 8, 1-6. doi: 10.1016/S1089-8603(02)00129-5

Genestra, M. S., Cysne-Finkelstein, L., Guedes-Silva, D., and Leon, L. L. (2003c). Effect of L-arginine analogs and a calcium chelator on nitric oxide (NO) production by Leishmania sp. J. Enzyme Inhib. Med. Chem. 18, 445-452. doi: 10.1080/1475636031000138787

Giraud, E., Martin, O., Yakob, L., and Rogers, M. (2019). Quantifying Leishmania metacyclic promastigotes from individual sandfly bites reveals the efficiency of vector transmission. Commun. Biol. 2:84. doi: 10.1038/s42003-019-0323-8

Guimarães-Costa, A. B., De Souza-Vieira, T. S., Paletta-Silva, R., FreitasMesquita, A. L., Meyer-Fernandes, J. R., and Saraiva, E. M. (2014). 3'-nucleotidase/nuclease activity allows Leishmania parasites to escape killing by neutrophil extracellular traps. Infect. Immun. 82, 1732-1740. doi: 10.1128/IAI.01232-13
Guimarães-Costa, A. B., Nascimento, M. T., Froment, G. S., Soares, R. P., Morgado, F. N., Conceição-Silva, F., et al. (2009). Leishmania amazonensis promastigotes induce and are killed by neutrophil extracellular traps. Proc. Natl. Acad. Sci. U.S.A. 106, 6748-6753. doi: 10.1073/pnas.0900226106

Guimarães-Costa, A. B., Rochael, N. C., Oliveira, F., Echevarria-Lima, J., and Saraiva, E. M. (2017). Neutrophil extracellular traps reprogram IL-4/GM-CSFinduced monocyte differentiation to anti-inflammatory macrophages. Front. Immunol. 8:523. doi: 10.3389/fimmu.2017.00523

Hammami, A., Charpentier, T., Smans, M., and Stäger, S. (2015). IRF-5-mediated inflammation limits CD $8+\mathrm{T}$ cell expansion by inducing HIF- $1 \alpha$ and impairing dendritic cell functions during Leishmania infection. PLoS Pathog. 11:e1004938. doi: 10.1371/journal.ppat.1004938

Hartley, M. A., Eren, R. O., Rossi, M., Prevel, F., Castiglioni, P., Isorce, N., et al. (2018). Leishmania guyanensis parasites block the activation of the inflammasome by inhibiting maturation of IL-1 $\beta$. Microb. Cell. 5, 137-149. doi: 10.15698/mic2018.03.619

Henn, G. A. L., Ramos Júnior, A. N., Colares, J. K. B., Mendes, L. P., Silveira, J. G. C., Lima, A. A. F., et al. (2018). Is visceral Leishmaniasis the same in HIV-coinfected adults? Braz. J. Infect. Dis. 22, 92-98. doi: 10.1016/j.bjid.2018. 03.001

Hermoso, T., Fishelson, Z., Becker, S. I., Hirschberg, K., and Jaffe, C. L. (1991). Leishmanial protein kinases phosphorylate components of the complement system. EMBO J. 10, 4061-4067. doi: 10.1002/j.1460-2075.1991.tb04982.x

Holowka, T., Castilho, T. M., Garcia, A. B., Sun, T., McMahon-Pratt, D., and Bucala, R. (2016). Leishmania-encoded orthologs of macrophage migration inhibitory factor regulate host immunity to promote parasite persistence. FASEB J. 30, 2249-2265. doi: 10.1096/fj.201500189R

Hu, S., Marshall, C., Darby, J., Wei, W., Lyons, A. B., and Körner, H. (2018). Absence of tumor necrosis factor supports alternative activation of macrophages in the liver after infection with Leishmania major. Front. Immunol. 9:1. doi: 10.3389/fimmu.2018.00001

Husein, A., Jamal, A., Ahmed, M. Z., Arish, M., Ali, R., Tabrez, S., et al. (2018). Leishmania donovani infection differentially regulates small G-proteins. J. Cell. Biochem. 119, 7844-7854. doi: 10.1002/jcb.27186

Ibraim, I. C., de Assis, R. R., Pessoa, N. L., Campos, M. A., Melo, M. N., Turco, S. J., et al. (2013). Two biochemically distinct lipophosphoglycans from Leishmania braziliensis and Leishmania infantum trigger different innate immune responses in murine macrophages. Parasit. Vect. 6:54. doi: 10.1186/1756-3305-6-54

Joshi, T., Rodriguez, S., Perovic, V., Cockburn, I. A., and Stäger, S. (2009). B7$\mathrm{H} 1$ blockade increases survival of dysfunctional CD8(+) T cells and confers protection against Leishmania donovani infections. PLoS Pathog. 5:e1000431. doi: 10.1371/journal.ppat.1000431

Kennedy, A. D., and De Leo, F. R. (2009). Neutrophil apoptosis and the resolution of infection. Immunol. Res. 43, 25-61. doi: 10.1007/s12026-008-8049-6

Kerr, D., Tietjen, G. T., Gong, Z., Tajkhorshid, E., Adams, E. J., and Lee, K. Y. C. (2018). Sensitivity of peripheral membrane proteins to the membrane context: a case study of phosphatidylserine and the TIM proteins. BBA 1860, 2126-2133. doi: 10.1016/j.bbamem.2018.06.010

Khodadadi, A., Rahdar, M., Hossainpour, A., and Khademvatan, S. (2013). An in vitro study on suppressive effects of Leishmania major on IL-2R $\alpha$ expression on peripheral human T lymphocyte. Trop. Biomed. 30, 526-534.

Khouri, R., Santos, G. S., Soares, G., Costa, J. M., Barral, A., Barral-Netto, M., et al. (2014). SOD1 plasma level as a biomarker for therapeutic failure in cutaneous leishmaniasis. J. Infect. Dis. 210, 306-310. doi: 10.1093/infdis/jiu087

Kima, P. E., Constant, S. L., Hannum, L., Colmenares, M., Lee, K. S., Haberman, A. M., et al. (2000). Internalization of Leishmania mexicana complex amastigotes via the Fc receptor is required to sustain infection in murine cutaneous leishmaniasis. J. Exp. Med. 191, 1063-1068. doi: 10.1084/jem.191.6.1063

Kong, F., Saldarriaga, O. A., Spratt, H., Osorio, E. Y., Travi, B. L., Luxon, B. A., et al. (2017). Transcriptional profiling in experimental visceral Leishmaniasis reveals a broad splenic inflammatory environment that conditions macrophages toward a disease-promoting phenotype. PLoS Pathog. 13:e1006165. doi: 10.1371/journal.ppat.1006165

Kropf, P., Freudenberg, M. A., Modolell, M., Price, H. P., Herath, S., Antoniazi, S., et al. (2004). Toll-like receptor 4 contributes to efficient control of infection with the protozoan parasite Leishmania major. Infect. Immun. 72, 1920-1928. doi: 10.1128/IAI.72.4.1920-1928.2004 
Kumar, A., Das, S., Mandal, A., Verma, S., Abhishek, K., Kumar, A., et al. (2018). Leishmania infection activates host mTOR for its survival by M2 macrophage polarization. Parasite Immunol. 40:e12586. doi: 10.1111/pim.12586

Launois, P., Louis, J. A., and Milon, G. (1997). The fate and persistence of Leishmania major in mice of different genetic backgrounds: an example of exploitation of the immune system by intracellular parasites. Parasitology 115 (Suppl):S25-S32. doi: 10.1017/S0031182097001777

Lee, S. H., Charmoy, M., Romano, A., Paun, A., Chaves, M. M., Cope, F. O., et al. (2018). Mannose receptor high, M2 dermal macrophages mediate nonhealing Leishmania major infection in a Th1 immune environment. J. Exp. Med. 215, 357-375. doi: 10.1084/jem.20171389

Leite, P. M., Gomes, R. S., Figueiredo, A. B., Serafim, T. D., Tafuri, W. L., de Souza, C. C., et al. (2012). Ecto-nucleotidase activities of promastigotes from Leishmania (Viannia) braziliensis relates to parasite infectivity and disease clinical outcome. PLoS Negl. Trop. Dis. 6:e1850. doi: 10.1371/journal.pntd.0001850

Lerner, E. A., Ribeiro, J. M., Nelson, R. J., and Lerner, M. R. (1991). Isolation of maxadilan, a potent vasodilatory peptide from the salivary glands of the sand fly Lutzomyia longipalpis. J. Biol. Chem. 266, 11234-11236.

Lima, M. H. F., Sacramento, L. A., Quirino, G. F. S., Ferreira, M. D., Benevides, L., Santana, A. K. M., et al. (2017). Leishmania infantum parasites subvert the host inflammatory response through the Adenosine A2A receptor to promote the establishment of infection. Front. Immunol. 8:815. doi: 10.3389/fimmu.2017.00815

Liu, Y., Liu, S., He, B., Wang, T., Zhao, S., Wu, C., et al. (2018). PD-1 blockade inhibits lymphocyte apoptosis and restores proliferation and anti-viral immune functions of lymphocyte after CP and NCP BVDV infection in vitro. Vet Microbiol. 226, 74-80. doi: 10.1016/j.vetmic.2018.10.014

Magalhães, L. S., Bomfim, L. G., Mota, S. G., Cruz, G. S., Corrêa, C. B., Tanajura, D. M., et al. (2018). Increased thiol levels in antimony-resistant Leishmania infantum isolated from treatment-refractory visceral leishmaniasis in Brazil. Mem. Inst. Oswaldo Cruz. 113, 119-125. doi: 10.1590/0074-02760 170289

Maia, Z., Lírio, M., Mistro, S., Mendes, C. M., Mehta, S. R., and Badaro, R. (2012). Comparative study of rK39 Leishmania antigen for serodiagnosis of visceral leishmaniasis: systematic review with meta-analysis. PLoS Negl. Trop. Dis. 6:e1484. doi: 10.1371/journal.pntd.0001484

Mandell, M. A., and Beverley, S. M. (2016). Concomitant immunity induced by persistent Leishmania major does not preclude secondary re-infection: implications for genetic exchange, diversity and vaccination. PLoS Negl. Trop. Dis. 10:e0004811. doi: 10.1371/journal.pntd.0004811

Mandell, M. A., and Beverley, S. M. (2017). Continual renewal and replication of persistent Leishmania major parasites in concomitantly immune hosts. Proc. Natl. Acad. Sci. U.S.A. 114, E801-E810. doi: 10.1073/pnas.1619265114

Martinez, J. E., Alba Arias, L., Escobar, M. A., and Saravia, N. G. (1992). Haemoculture of Leishmania (Viannia) braziliensis from two cases of mucosal Leishmaniasis: re-examination of haematogenous dissemination. Trans. $R$ Soc. Trop. Med. Hyg. 86, 392-394. doi: 10.1016/0035-9203(92)90233-3

Martinéz-Valencia, A. J., Daza-Rivera, C. F., Rosales-Chilama, M., Cossio, A., Casadiego Rincón, E. J., Desai, M. M., et al. (2017). Clinical and parasitological factors in parasite persistence after treatment and clinical cure of cutaneous leishmaniasis. PLoS Negl. Trop. Dis. 11:e0005713. doi: 10.1371/journal.pntd.0005713

Matheoud, D., Moradin, N., Bellemare-Pelletier, A., Shio, M. T., Hong, W. J., Olivier, M., et al. (2013). Leishmania evades host immunity by inhibiting antigen cross-presentation through direct cleavage of the SNARE VAMP8. Cell Host Microbe 14, 15-25. doi: 10.1016/j.chom.2013.06.003

Medina-Colorado, A. A., Osorio, E. Y., Saldarriaga, O. A., Travi, B. L., Kong, F., Spratt, H., et al. (2017). Splenic CD4+ T cells in progressive visceral leishmaniasis show a mixed effector-regulatory phenotype and impair macrophage effector function through inhibitory receptor expression. PLoS ONE 12:e0169496. doi: 10.1371/journal.pone.0169496

Mishra, J., Madhubala, R., and Singh, S. (2013). Visceral and post-KalaAzar dermal leishmaniasis isolates show significant difference in their in vitro drug susceptibility pattern. Parasitol. Res. 112, 1001-1009. doi: 10.1007/s00436-012-3222-1

Mondelaers, A., Sanchez-Cañete, M. P., Hendrickx, S., Eberhardt, E., Garcia-Hernandez, R., Lachaud, L., et al. (2016). Genomic and molecular characterization of miltefosine resistance in Leishmania infantum strains with either natural or acquired resistance through experimental selection of intracellular amastigotes. PLOS ONE 11:e0154101. doi: 10.1371/journal.pone.0154101

Morato, C. I., da Silva, I. A. Jr, Borges, A. F., Dorta, M. L., Oliveira, M. A., Jancar, S., et al. (2014). Essential role of leukotriene B4 on Leishmania (Viannia) braziliensis killing by human macrophages. Microbes Infect. 16, 945-953. doi: 10.1016/j.micinf.2014.08.015

Moreira, D., Rodrigues, V., Abengozar, M., Rivas, L., Rial, E., Laforge, M., et al. (2015). Leishmania infantum modulates host macrophage mitochondrial metabolism by hijacking the SIRT1-AMPK axis. PLoS Pathog. 11:e1004684. doi: 10.1371/journal.ppat.1004684

Moreira, P. R., Bandarra, M., Magalhães, G. M., Munari, D. P., Machado, G. F., and Prandini, M. M. (2013). Influence of apoptosis on the cutaneous and peripheral lymph node inflammatory response in dogs with visceral leishmaniasis. Vet. Parasitol. 192, 149-157. doi: 10.1016/j.vetpar.2012.09.029

Moreira, P. R., Fernando, F. S., Montassier, H. J., André, M. R., and de Oliveira Vasconcelos, R. (2016). Polarized M2 macrophages in dogs with visceral leishmaniasis. Vet. Parasitol. 226, 69-73. doi: 10.1016/j.vetpar.2016. 06.032

Morgado, F. N., Nascimento, M. T., Saraiva, E. M., de Oliveira-Ribeiro, C., Madeira, M., and da Costa-Santos, M. (2015). Are neutrophil extracellular traps playing a role in the parasite control in active American tegumentary Leishmaniasis lesions? PLoS ONE 10:e0133063. doi: 10.1371/journal.pone.0133063

Morgado, F. N., Schubach, A., Vasconcellos, E., Azeredo-Coutinho, R. B., Valete-Rosalino, C. M., Quintella, L. P., et al. (2010). Signs of an in situ inflammatory reaction in scars of human American tegumentary leishmaniasis. Parasite Immunol. 32, 285-295. doi: 10.1111/j.1365-3024.2009. 01188.x

Morris, R. V., Shoemaker, C. B., David, J. R., Lanzaro, G. C., and Titus, R. G. (2001). Sandfly maxadilan exacerbates infection with Leishmania major and vaccinating against it protects against L. Major infection. J. Immunol. 167, 5226-5230. doi: 10.4049/jimmunol.167.9.5226

Moshrefi, M., Spotin, A., Kafil, H. S., Mahami-Oskouei, M., Baradaran, B., Ahmadpour, E., et al. (2017). Tumor suppressor p53 induces apoptosis of host lymphocytes experimentally infected by Leishmania major, by activation of Bax and caspase-3: a possible survival mechanism for the parasite. Parasitol. Res. 116, 2159-2166. doi: 10.1007/s00436-017-5517-8

Muniz-Junqueira, M. I., and de Paula-Coelho, V. N. (2008). Meglumine antimonate directly increases phagocytosis, superoxide anion and TNFalpha production, but only via TNF-alpha it indirectly increases nitric oxide production by phagocytes of healthy individuals, in vitro. Int. Immunopharmacol. 8, 1633-1638. doi: 10.1016/j.intimp.2008.07.011

Murphy, M. L., Cotterell, S. E., Gorak, P. M., Engwerda, C. R., and Kaye, P. M. (1998). Blockade of CTLA-4 enhances host resistance to the intracellular pathogen, Leishmania donovani. J. Immunol. 161, 4153-4160.

Neves, B. M., Silvestre, R., Resende, M., Ouaissi, A., Cunha, J., Tavares, J., et al. (2010). Activation of phosphatidylinositol 3-kinase/Akt and impairment of nuclear factor-kappaB: molecular mechanisms behind the arrested maturation/activation state of Leishmania infantum-infected dendritic cells. Am. J. Pathol. 177, 2898-2911. doi: 10.2353/ajpath.2010.100367

Novais, F. O., Carvalho, A. M., Clark, M. L., Carvalho, L. P., Beiting, D. P., Brodsky, I. E., et al. (2017). CD8+ T cell cytotoxicity mediates pathology in the skin by inflammasome activation and IL-1 $\beta$ production. PLoS Pathog. 13:e1006196. doi: 10.1371/journal.ppat.1006196

Okwor, I., and Uzonna, J. (2008). Persistent parasites and immunologic memory in cutaneous Leishmaniasis: implications for vaccine designs and vaccination strategies. Immunol. Res. 41, 123-136. doi: 10.1007/s12026-0088016-2

Oliveira, F., Lawyer, P. G., Kamhawi, S., and Valenzuela, J. G. (2008). Immunity to distinct sand fly salivary proteins primes the anti-Leishmania immune response towards protection or exacerbation of disease. PLoS Negl. Trop. Dis. 2:e226. doi: 10.1371/journal.pntd.0000226

Paduch, K., Debus, A., Rai, B., Schleicher, U., and Bogdan, C. (2019). Resolution of cutaneous Leishmaniasis and persistence of Leishmania major in the absence of arginase 1. J. Immunol. 202, 1453-1464. doi: 10.4049/jimmunol.18 01249 
Passos, S., Carvalho, L. P., Costa, R. S., Campos, T. M., Novais, F. O., Magalhães, A., et al. (2015). Intermediate monocytes contribute to pathologic immune response in Leishmania braziliensis infections. J. Infect. Dis. 211, 274-282. doi: 10.1093/infdis/jiu439

Peters, N. C., Egen, J. G., Secundino, N., Debrabant, A., Kimblin, N., Kamhawi, S., et al. (2008). In vivo imaging reveals an essential role for neutrophils in Leishmaniasis transmitted by sand flies. Science 321, 970-974. doi: 10.1126/science.1159194

Peters, N. C., and Sacks, D. L. (2009). The impact of vector-mediated neutrophil recruitment on cutaneous Leishmaniasis. Cell Microbiol. 11, 1290-1296. doi: 10.1111/j.1462-5822.2009.01348.x

Plagge, M., and Laskay, T. (2017). Early production of the neutrophil-derived lipid mediators LTB4 and LXA4 is modulated by intracellular infection with Leishmania major. Biomed. Res. Int. 2017:2014583. doi: 10.1155/2017/2014583

Pountain, A. W., Weidt, S. K., Regnault, C., Bates, P. A., Donachie, A. M., Dickens, N. J., et al. (2019). Genomic instability at the locus of sterol C24methyltransferase promotes amphotericin B resistance in Leishmania parasites. PLoS Negl. Trop. Dis. 13:e0007052. doi: 10.1371/journal.pntd.0007052

Prieto Barja, P., Pescher, P., Bussotti, G., Dumetz, F., Imamura, H., Kedra, D., et al. (2017). Haplotype selection as an adaptive mechanism in the protozoan pathogen Leishmania donovani. Nat. Ecol. Evol. 1, 1961-1969. doi: 10.1038/s41559-017-0361-x

Puentes, S. M., Da Silva, R. P., Sacks, D. L., Hammer, C. H., and Joiner, K. A. (1990). Serum resistance of metacyclic stage Leishmania major promastigotes is due to release of C5b-9. J. Immunol. 145, 4311-4316.

Rastrojo, A., García-Hernández, R., Vargas, P., Camacho, E., Corvo, L., Imamura, H., et al. (2018). Genomic and transcriptomic alterations in Leishmania donovani lines experimentally resistant to antileishmanial drugs. Int. J. Parasitol. Drug. Resist. 8, 246-264. doi: 10.1016/j.ijpddr.2018.04.002

Regli, I. B., Fernández, O. L., Martínez-Salazar, B., Gómez, M. A., Saravia, N. G., and Tacchini-Cottier, F. (2018). Resistance of Leishmania (Viannia) Panamensis to meglumine antimoniate or miltefosine modulates neutrophil effector functions. Front. Immunol. 9:3040. doi: 10.3389/fimmu.2018. 03040

Resende, M., Moreira, D., Augusto, J., Cunha, J., Neves, B., Cruz, M. T., et al. (2013). Leishmania-infected MHC class IIhigh dendritic cells polarize CD4+ T cells toward a nonprotective T-bet + IFN- $\gamma+$ IL-10+ phenotype. J. Immunol. 191, 262-273. doi: 10.4049/jimmunol.1203518

Ribeiro-Gomes, F. L., and Sacks, D. (2012). The influence of early neutrophilLeishmania interactions on the host immune response to infection. Front. Cell Infect. Microbiol. 2:59. doi: 10.3389/fcimb.2012.00059

Romero, I., Téllez, J., Suárez, Y., Cardona, M., Figueroa, R., Zelazny, A., et al. (2010). Viability and burden of Leishmania in extralesional sites during human dermal leishmaniasis. PLoS Negl. Trop. Dis. 4:e819. doi: 10.1371/journal.pntd.0000819

Rosales-Chilama, M., Gongora, R. E., Valderrama, L., Jojoa, J., Alexander, N., Rubiano, L. C., et al. (2015). Parasitological confirmation and analysis of Leishmania diversity in asymptomatic and subclinical infection following resolution of cutaneous Leishmaniasis. PLoS Negl. Trop. Dis. 9:e0004273. doi: 10.1371 /journal.pntd.0004273

Santos, D., Campos, T. M., Saldanha, M., Oliveira, S. C., Nascimento, M., Zamboni, D. S., et al. (2018). IL-1 $\beta$ production by intermediate monocytes is associated with immunopathology in cutaneous Leishmaniasis. J. Invest. Dermatol. 138, 1107-1115. doi: 10.1016/j.jid.2017.11.029

Singh, A. K., Das, V. N. R., Amit, A., Dikhit, M. R., Mahantesh, V., Singh, S. K., et al. (2018). Cytokines and chemokines differentially regulate innate immune cell trafficking during post kala-azar dermal leishmaniasis. J. Cell Biochem. 119, 7406-7418. doi: $10.1002 / j \mathrm{jcb} .27048$

Singh, R. P., Picado, A., Alam, S., Hasker, E., Singh, S. P., Ostyn, B., et al. (2012). Post-kala-azar dermal Leishmaniasis in visceral leishmaniasisendemic communities in Bihar, India. Trop. Med. Int. Health 17, 1345-1348. doi: 10.1111/j.1365-3156.2012.03067.x

Soares-Bezerra, R. J., Leon, L. L., Echevaria, A., Reis, C. M., Gomes-Silva, L., Agostinho, C. G., et al. (2013). In vitro evaluation of 4-phenyl-55(4'-X-phenyl)-1,3,4-thiadiazolium-2-phynylamide chlorides and 3[N-4'-Xphenyl]-1,2,3-oxadiazolium-5-olate derivatives on nitric oxide synthase and arginase activities of Leishmania amazonensis. Exp. Parasitol. 135, 50-54. doi: 10.1016/j.exppara.2013.05.008
Soulat, D., and Bogdan, C. (2017). Function of macrophage and parasite phosphatases in leishmaniasis. Front. Immunol. 8:1838. doi: 10.3389/fimmu.2017.01838

Späth, G. F., McDowell, M. A., and Beverley, S. M. (2008). Leishmania major intracellular survival is not altered in SHP-1 deficient mev or CD45-/- mice. Exp. Parasitol. 120, 275-279. doi: 10.1016/j.exppara.2008.07.003

Stenger, S., Donhauser, N., Thüring, H., Röllinghoff, M., and Bogdan, C. (1996). Reactivation of latent Leishmaniasis by inhibition of inducible nitric oxide synthase. J. Exp. Med. 183, 1501-1514. doi: 10.1084/jem.183.4.1501

Sudan, R., Srivastava, N., Pandey, S. P., Majumdar, S., and Saha, B. (2012). Reciprocal regulation of protein kinase $\mathrm{C}$ isoforms results in differential cellular responsiveness. J. Immunol. 188, 2328-2337. doi: 10.4049/jimmunol.1101678

Távora, L. G. F., Nogueira, M. B., and Gomes, S. T. (2015). Visceral Leishmaniasis/HIV co-infection in northeast Brazil: evaluation of outcome. Braz. J. Infect. Dis. 19, 651-656. doi: 10.1016/j.bjid.2015.07.004

Temporal, R. M., Cysne-Finkeltein, L., Echevarria, A., Silva-Gonçalves, A. J., Leon, L. L., and Genestra, M. S. (2005). Amidine derivatives and Leishmania amazonensis: na evaluation of the effect of nitric oxide (NO) production on the parasite-macrophage interaction. Enzyme Inhib. Med. Chem. 20, 13-18. doi: 10.1080/14756360400015207

Tomiotto-Pellissier, F., Bortoleti, B. T. D. S., Assolini, J. P., Gonçalves, M. D., Carloto, A. C. M., Miranda-Sapla, M. M., et al. (2018). Macrophage polarization in Leishmaniasis: broadening horizons. Front. Immunol. 9:2529. doi: 10.3389/fimmu.2018.02529

Trahtemberg, U., and Mevorach, D. (2017). Apoptotic cells induced signaling for immune homeostasis in macrophages and dendritic cells. Front. Immunol. 8:1356. doi: $10.3389 /$ fimmu.2017.01356

van Zandbergen, G., Klinger, M., Mueller, A., Dannenberg, S., Gebert, A., Solbach, W., et al. (2004). Cutting edge: neutrophil granulocyte serves as a vector for Leishmania entry into macrophages. J. Immunol. 173, 6521-6525. doi: 10.4049/jimmunol.173.11.6521

Vergel, C., Palacios, R., Cadena, H., Posso, C. J., Valderrama, L., Perez, M., et al. (2006). Evidence for Leishmania (viannia) parasites in the skin and blood of patients before and after treatment. J. Infect. Dis. 194, 503-511. doi: 10.1086/505583

Veronica, J., Chandrasekaran, S., Dayakar, A., Devender, M., Prajapati, V. K., Sundar, S., et al. (2019). Iron superoxide dismutase contributes to miltefosine resistance in Leishmania donovani. FEBS J. 286, 3488-3503. doi: $10.1111 /$ febs.14923

Viana, A. G., Magalhães, L. M. D., Giunchetti, R. C., Dutra, W. O., and Gollob, K. J. (2018). Infection of human monocytes with Leishmania infantum strains induces a downmodulated response when compared with infection with Leishmania braziliensis. Front. Immunol. 8:1896 doi: $10.3389 /$ fimmu.2017.01896

Viana, A. G., Magalhães, L. M. D., Giunchetti, R. C., Dutra, W. O., and Gollob, K. J. (2019). Leishmania infantum induces expression of the negative regulatory checkpoint, CTLA-4, by human naïve CD8+ T cells. Parasite Immunol. 24:e12659. doi: 10.1111/pim.12659

Wanderley, J. L., Pinto da Silva, L. H., Deolindo, P., Soong, L., Borges, V. M., Prates, D. B., et al. (2009). Cooperation between apoptotic and viable metacyclics enhances the pathogenesis of Leishmaniasis. PLoS ONE 4:e5733. doi: 10.1371/journal.pone.0005733

Wenzel, U. A., Bank, E., Florian, C., Förster, S., Zimara, N., Steinacker, J., et al. (2012). Leishmania major parasite stage-dependent host cell invasion and immune evasion. FASEB J. 26, 29-39. doi: 10.1096/fj.11184895

World Health Organization (WHO) (2010). Control of Leishmaniasis. IN: Repoprt of a meeting of the WHO expert committee on the control of leishmaniasis. Geneve (WHO Technical Report Series, 949).

World Health Organization [WHO] (2017). Global Leishmaniasis update, 2006-2015: a turning point in Leishmaniasis surveillance. Wkly. Epidemiol. Rec. $38,557-572$

World Wealth Assembly (WHA) (2007). Resolution From the $16^{\circ}$ World Health Assembly, May 21, 2007. Available online at: www.who.int/neglected_diseases/ mediacentre/WHA_60.13_Eng.pdf

Yadav, A., Amit, A., Chaudhary, R., Chandel, A. S., Mahantesh, V., Suman, S. S., et al. (2015). Leishmania donovani: impairment of the cellular immune response against recombinant ornithine decarboxylase protein as a possible 
evasion strategy of Leishmania in visceral leishmaniasis. Int. J. Parasitol. 45, 33-42. doi: 10.1016/j.ijpara.2014.08.013

Yasur-Landau, D., Jaffe, C. L., David, L., Doron-Faigenboim, A., and Baneth, G. (2018). Resistance of Leishmania infantum to allopurinol is associated with chromosome and gene copy number variations including decrease in the S-adenosylmethionine synthetase (METK) gene copy number. Int. J. Parasitol. Drugs Drug Resist. 8, 403-410. doi: 10.1016/j.ijpddr.2018. 08.002

Zijlstra, E. E. (2016). The immunology of post-kala-azar dermal leishmaniasis (PKDL). Parasites Vect. 9:464. doi: 10.1186/s13071-016$1721-0$
Conflict of Interest: The authors declare that the research was conducted in the absence of any commercial or financial relationships that could be construed as a potential conflict of interest.

Copyright $\odot 2019$ Conceição-Silva and Morgado. This is an open-access article distributed under the terms of the Creative Commons Attribution License (CC BY). The use, distribution or reproduction in other forums is permitted, provided the original author(s) and the copyright owner(s) are credited and that the original publication in this journal is cited, in accordance with accepted academic practice. No use, distribution or reproduction is permitted which does not comply with these terms. 